\title{
Highly Regio- and Diastereoselective Tethered Aza-Wacker Cycliza- tions of Alkenyl Phosphoramidates
}

\author{
Anand H. Shinde ${ }^{a \dagger}$, Annu Anna Thomas ${ }^{a \dagger}$, Joel T. Mague ${ }^{b}$, and Shyam Sathyamoorthi*a \\ † equal contribution \\ aDepartment of Medicinal Chemistry, University of Kansas, Lawrence, Kansas, USA. b Department of Chemistry, Tulane \\ University, New Orleans, Louisiana, USA.
}

\begin{abstract}
We present highly diastereoselective tethered aza-Wacker cyclization reactions of alkenyl phosphoramidates. "Arming" the phosphoramidate tether with 5-chloro8-quinolinol was essential to achieving $>20: 1$ diastereoselectivity in these reactions. The substrate scope with respect to alkenyl alcohols and phosphoramidate tether was extensively explored. The scalability of the oxidative cyclization was demonstrated, and the product cyclophosphoramidates were shown to be valuable synthons, including for tether removal. With chiral alkenyl precursors, enantiopure cyclic phosphoramidates were formed.
\end{abstract}

\section{Introduction}

The regioselective functionalization of olefins remains an area of intense research activity. ${ }^{1-9}$ While intermolecular olefin functionalization reactions often rely on subtle steric and electronic effects for selectivity, intramolecular reactions are generally much more predictable due to geometric constraints. A particularly powerful class of intramolecular olefin functionalization reactions is the tethered aza-Wacker cyclization. ${ }^{10-}$

${ }^{17}$ In such reactions, a nitrogen containing auxiliary ("the tether") is appended to an alkenyl alcohol prior to the cyclization event.

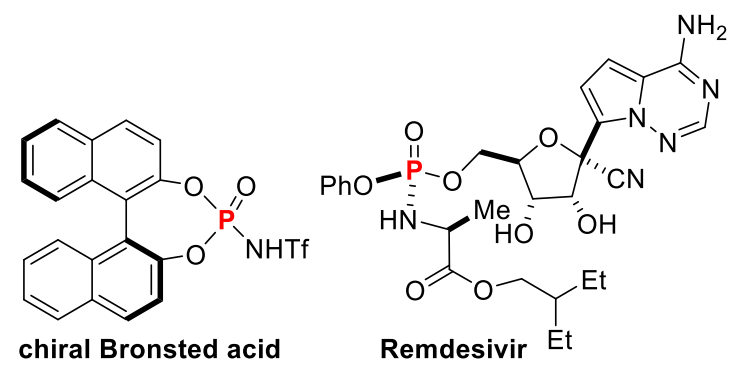

Figure 1. Phosphoramidates are indispensable to catalysis and medicine.

Tethered $a z a$-Wacker cyclization reactions are enabling because they free the synthetic practitioner from the constraint of needing a pre-existing $\mathrm{C}-\mathrm{N}$ bond in order to forge a new one. ${ }^{18,19}$

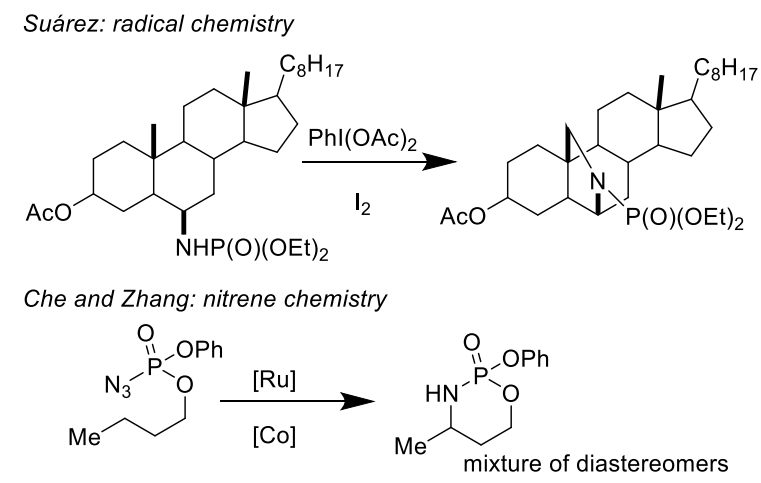

This Work: chelate-controlled tethered aza-Wacker chemistry

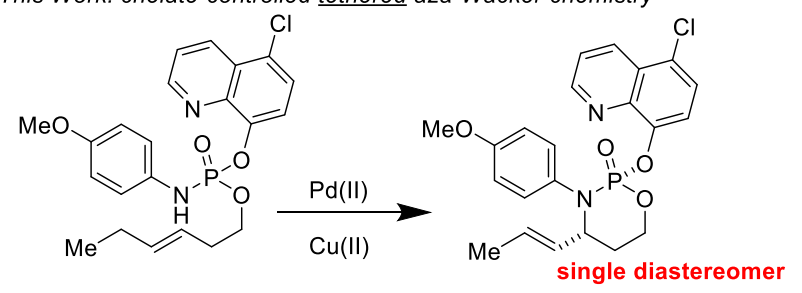

Scheme 1. Oxidative Strategies for Phosphoramidate Construction.

Phosphoramidates are an important class of heteroatom-rich compounds, and its members have found applications in diverse fields, ranging from asymmetric catalysis $^{20}$ to medicinal chemistry ${ }^{21}$ (Figure 1). Cyclic phosphoramidates are traditionally assembled from condensation of amino-alcohols with phosphoryl chlorides, requiring precursor molecules with both amino and alcohol functionalities pre-installed. We envisioned developing a tethered $a z a-$ Wacker protocol for the synthesis of such heterocycles, allowing for the attachment of a phosphoramidate auxiliary to alkenyl alcohols and subsequent oxidative cyclization. There is sparse precedent for the use of oxidation reactions in cyclo-phosphoramidate construction. To date, such reactions have largely been restricted to phosphoryl azide decomposition with subsequent nitrene insertion ${ }^{22,23}$ and radical Suárez-type oxidations with $\mathrm{Pb}(\mathrm{OAc})_{4}$ or $\mathrm{PhI}(\mathrm{OAc})_{2} / \mathrm{I}_{2}$ (Scheme 1). ${ }^{24-}$ 
${ }^{27}$ Diastereocontrol remains a challenge with these reactions, with many of these protocols furnishing mixtures of diastereomers. We have found that "arming" the phosphoramidate tether with an unusual chloroquinolinol auxiliary allows for complete diastereocontrol during the cyclization event. The use of palladiumchelating auxiliaries is well known in the related field of $\mathrm{C}-\mathrm{H}$ activation, ${ }^{28-32}$ and the Engle group has shown that amino-quinolines appended to amides are excellent for regio-control in olefin mono- and di-functionalization reactions. ${ }^{33-36}$ To our knowledge, ours is the first example of the use of an auxiliary to control diastereoselectivity in an olefin functionalization process.

\section{Results and Discussion}

Table 1. Reaction Optimization.

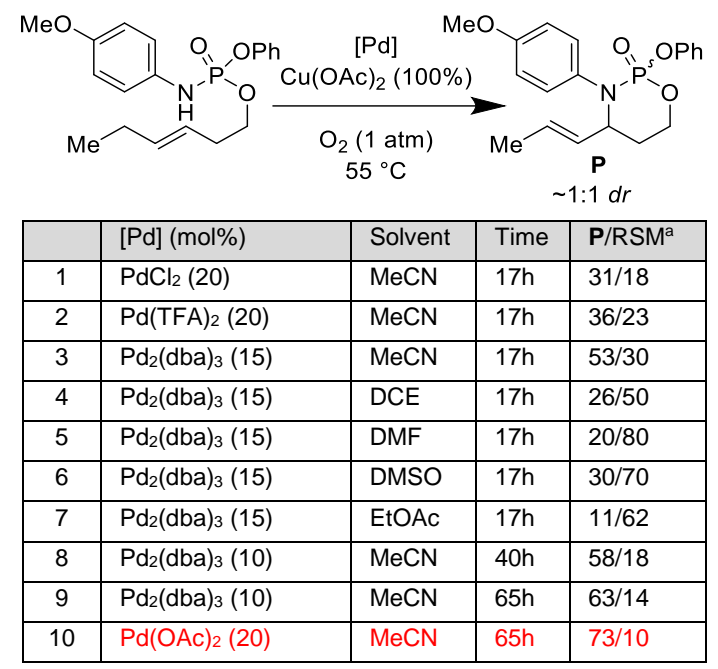

aPercent product estimated from ${ }^{1} \mathrm{H}$ NMR integration with 1,3,5-trimethoxybenzene as an internal standard.

We began optimizing the reaction with $(\mathrm{E})$ hex-3-en-1-yl phenyl (4-methoxyphenyl)phosphoramidate, readily prepared from condensation of commercially available trans-3-hexen-1-ol and anisidine with phenyl dichlorophosphate. Product formation was observed with $20 \mathrm{~mol} \% \mathrm{PdCl}_{2}$ in $\mathrm{MeCN}$ (Table 1, Entry 1), giving us hope that our envisioned oxidative cyclization reaction was viable. We saw little improvement upon switching to $\operatorname{Pd}(\mathrm{TFA})_{2}$ (Table 1, Entry 2), but product formation did increase with $\mathrm{Pd}_{2}(\mathrm{dba})_{3}$ (Table 1, Entry 3). Solvents other than $\mathrm{MeCN}$ were invariably deleterious (Table 1, Entries 4-7). Increasing the reaction time led to the most marked improvement in performance (Table 1, Entries 8-10). Our optimized protocol involved heating substrate, $20 \mathrm{~mol} \%$ $\mathrm{Pd}(\mathrm{OAc})_{2}$, and 1 equivalent of $\mathrm{Cu}(\mathrm{OAc})$ to $55^{\circ} \mathrm{C}$ in $\mathrm{MeCN}$ for 65 hours (Table 1, Entry 10). In all cases, product was furnished as a roughly 1:1 diastereomeric mixture.
Scheme 2. Aniline-reactivity relationship.

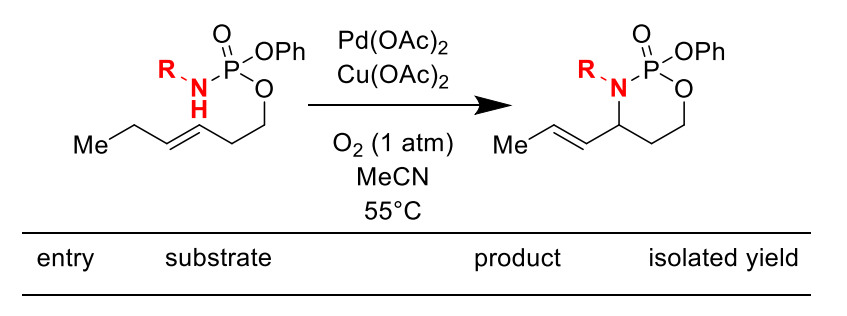<smiles>CCC=CCCOP(=O)(Nc1ccc(OC)cc1)Oc1ccccc1</smiles>

$\mathrm{MeO}$

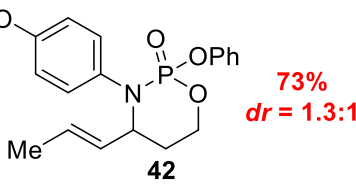

2<smiles>CCCCCOP(=O)(Nc1ccc2c(c1)OCO2)Oc1ccccc1</smiles><smiles>COC=CC1[C@@H](C)COP(=O)(c2ccccc2)N1c1ccc2c(c1)OCO2</smiles>

3<smiles>CC/C=C/CCOP(=O)(Nc1ccc(OC)c(OC)c1)c1ccccc1</smiles>

4<smiles>CCCCCOP(=O)(Nc1cc(C)cc(C)c1)Oc1ccccc1</smiles><smiles>C/C=C/C1CCOP(=O)(c2ccccc2)N1c1ccc(OC)c(OC)c1</smiles>

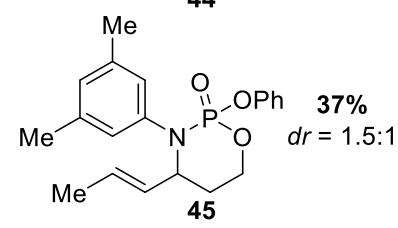

5<smiles>CCC=CCCOP(=O)(Nc1ccc(OCC)cc1)Oc1ccccc1</smiles>

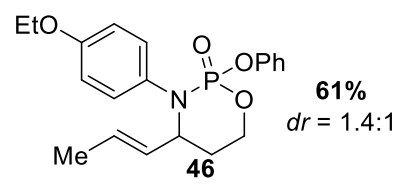<smiles>CC/C=C/CCOP(=O)(Nc1ccc(OC)cc1OC)Oc1ccccc1</smiles><smiles>C/C=C/C1[Z7]COP(=O)(Oc2ccccc2)N1c1ccc(OC)cc1OC</smiles>

7<smiles>CC/C=C/CCOP(=O)(Nc1ccc(C)cc1)Oc1ccccc1</smiles><smiles>C/C=C/C1[C@H](C)COP(=O)(Oc2ccccc2)N1c1ccc(C)cc1</smiles>

8<smiles>CC/C=C/CCOP(=O)(Nc1ccccc1)Oc1ccccc1</smiles>

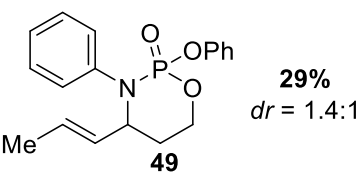

Reaction conditions: $\mathrm{Pd}(\mathrm{OAc})_{2}(20 \mathrm{~mol} \%), \mathrm{Cu}(\mathrm{OAc})_{2}$ (1 equiv.), $\mathrm{O}_{2}$ (1 atm), $\mathrm{CH}_{3} \mathrm{CN}, 55^{\circ} \mathrm{C}, 65 \mathrm{~h}$

Our optimized protocol was not limited to phosphoramidates containing anisidine (Scheme 2). We were pleased to see reasonable yields with phosphoramidates constructed from 3,4- 
methylenedioxyaniline (Scheme 2, Entry 2), 3,4-dimethoxyaniline (Scheme 2, Entry 3), p-ethoxyaniline (Scheme 2, Entry 5), and toluidine (Scheme 2, Entry 7). From these structure-reactivity relationship studies, it was clear that electron rich anilines performed much better than electron neutral (Scheme 2, Entry 8) ones. Steric factors also played an important role, with 2,4dimethoxyaniline performing poorly (Scheme 2, Entry 6). In all cases, diastereoselectivity ranged from $\sim 1: 1$ to $\sim 2: 1$.

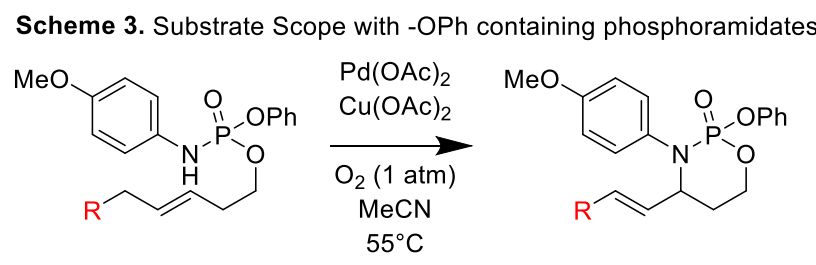

\begin{tabular}{|c|c|c|c|}
\hline entry & substrate & product & isolated yield \\
\hline
\end{tabular}<smiles>C=CC1CCOP(=O)(Oc2ccccc2)N1c1ccc(OC)cc1</smiles><smiles>COc1ccc(NP(=O)(OCC/C=C/Cc2ccccc2)Oc2ccccc2)cc1</smiles><smiles>C/C=C\C(=O)N(c1ccc(OC)cc1)P(=O)(OCCC)Oc1ccccc1</smiles>

4<smiles>COc1ccc(NP(=O)(OCC/C=C/Cc2ccc(F)cc2)OP(=O)(c2ccccc2)c2ccc(OC)cc2)cc1</smiles>

Reaction conditions: $\mathrm{Pd}(\mathrm{OAc})_{2}(20 \mathrm{~mol} \%), \mathrm{Cu}(\mathrm{OAc})_{2}$ (1 equiv.), $\mathrm{O}_{2}$ (1 atm), $\mathrm{CH}_{3} \mathrm{CN}, 55^{\circ} \mathrm{C}, 65 \mathrm{~h}$

A brief survey of alkenyl alcohols with our optimized protocol (Scheme 3) showed that substrates other than those derived from trans-hexen-3-ol were fully compatible. Nevertheless, each product was furnished as a mixture of diastereomers. Thus, we concluded that reaction diastereoselectivity was largely insensitive to the nature of the alkenyl alcohol.

We next explored the effect of changing the - $\mathrm{OPh}$ arm of the phosphoramidate auxiliary (Scheme 4). Product formation was viable with a variety of phenoxides and alkoxides. Electron-deficient phenoxides (Scheme 4, Entries 3-4) afforded better reactions than
Scheme 4. Changing the alkoxy substituent.

$$
\text { (1) }
$$

\begin{tabular}{|c|c|c|c|}
\hline entry & substrate & product & isolated yielc \\
\hline
\end{tabular}
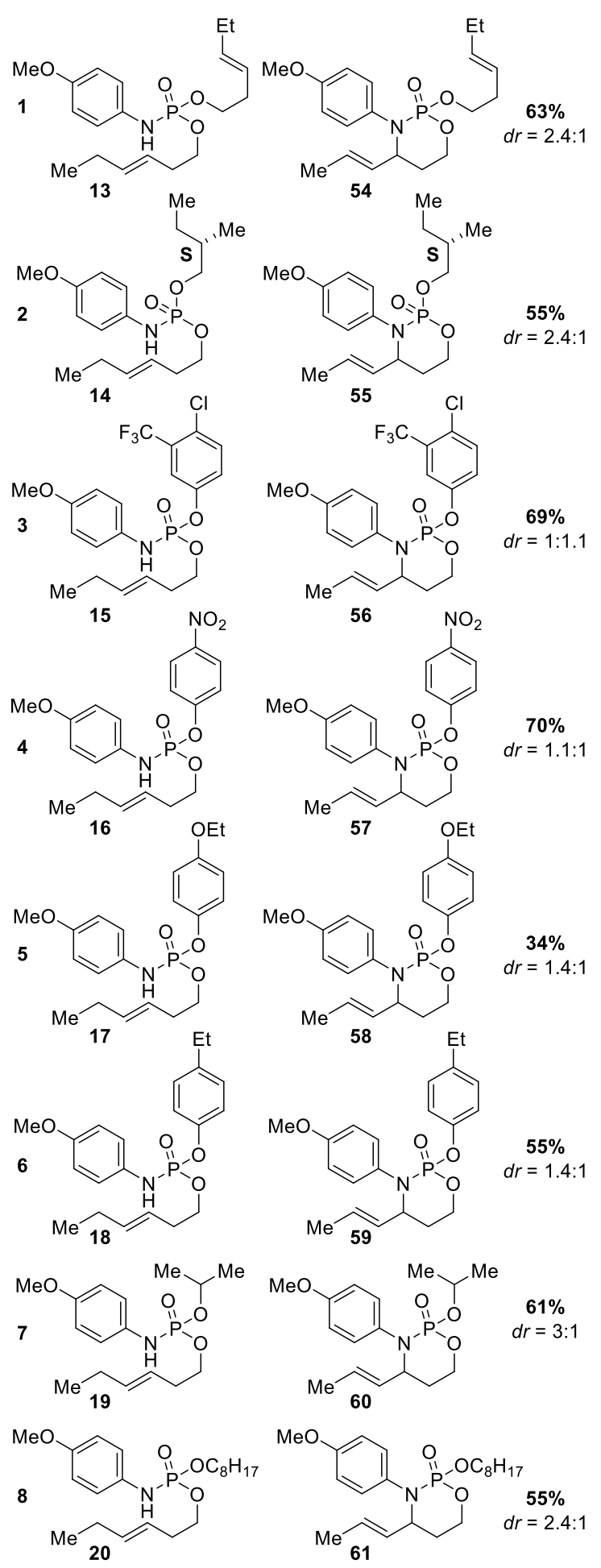

Reaction conditions: $\mathrm{Pd}(\mathrm{OAc})_{2}(20 \mathrm{~mol} \%), \mathrm{Cu}(\mathrm{OAc})_{2}$ (1 equiv.), $\mathrm{O}_{2}(1 \mathrm{~atm}), \mathrm{CH}_{3} \mathrm{CN}, 55^{\circ} \mathrm{C}, 65 \mathrm{~h}$

electron rich ones (Scheme 4, Entries 5-6). Even 
with a chiral auxiliary (Scheme 4, Entry 2) or with a secondary alkoxide (Scheme 4, Entry 7), we were unable to break a diastereomeric barrier of $~ 3: 1$.

Collectively, these results informed us that we were unlikely to further optimize the diastereoselectivity of this oxidative cyclization by tuning simple steric and electronic factors. Inspired by the use of palladium-chelating auxiliaries in $\mathrm{C}-\mathrm{H}$ activation and Engle's work on regioselective alkene functionalization with amido-quinolines, we wondered if a chelate approach would resolve the diastereoselectivity problem. We hypothesized that a chelate as depicted in Scheme 5 would likely transform our diastereolabile reaction into a fully diastereoselective one. We heated one equivalent of $\mathrm{Pd}(\mathrm{OAc})_{2}$ with 21 to $55{ }^{\circ} \mathrm{C}$ in acetonitrile and analyzed an aliquot of the reaction mixture by high resolution mass spectrometry. To our delight, we identified the molecular ion corresponding to our proposed chelate.

\section{Diastereocontrolled}
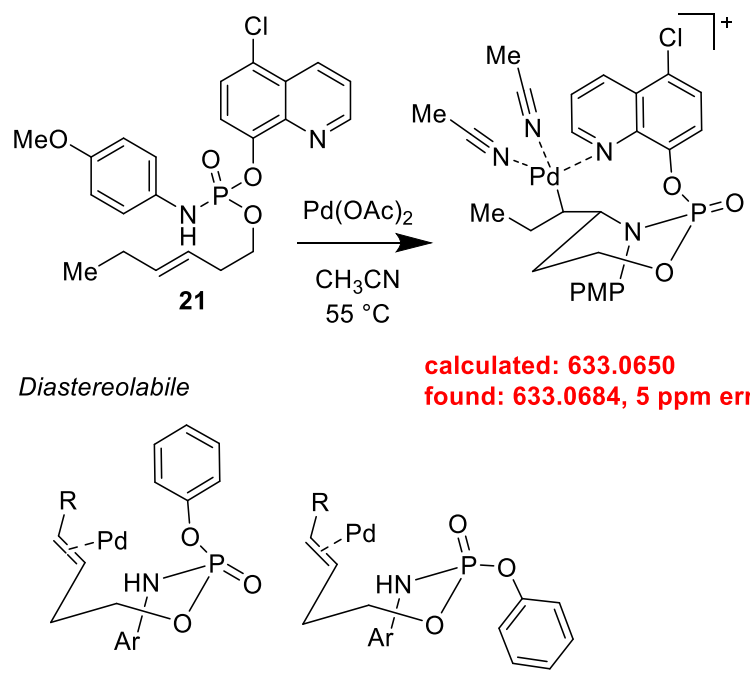

Scheme 5. HRMS analysis identifies a putative chelate for diastereocontrol in the oxidative cyclization.

We thus examined a range of quinolinol auxiliaries (Scheme 6). We found that phosphoramidate tethers containing a 5-chloro-8-quinolinoxide arm afforded cyclized product in good yields and, most importantly, as a single diastereomer (Scheme 6, Entry 1). At present, the differential performance of 5chloro-8-quinolinol relative to other quinolinol auxiliaries (Scheme 6, Entries 2-3) remains unexplained. The presence of a nitrogen, presumably critical for palladium chelation, was essential for diastereoselectivity. With naphthoxide (Scheme 6, Entry 4), a 1:1 mixture of diastereomers re-emerged.

The phosphoramidate tether containing a 5chloro-8-quinolinoxide arm was compatible with a wide range of alkenyl alcohols (Scheme 7). Alkenyl alcohols containing aryl rings adorned with $-\mathrm{CF}_{3}$, $\mathrm{NMe}_{2}$, -OMe groups all reacted smoothly (Scheme 7, Entry 1). Heterocycles such as furan and thiophene

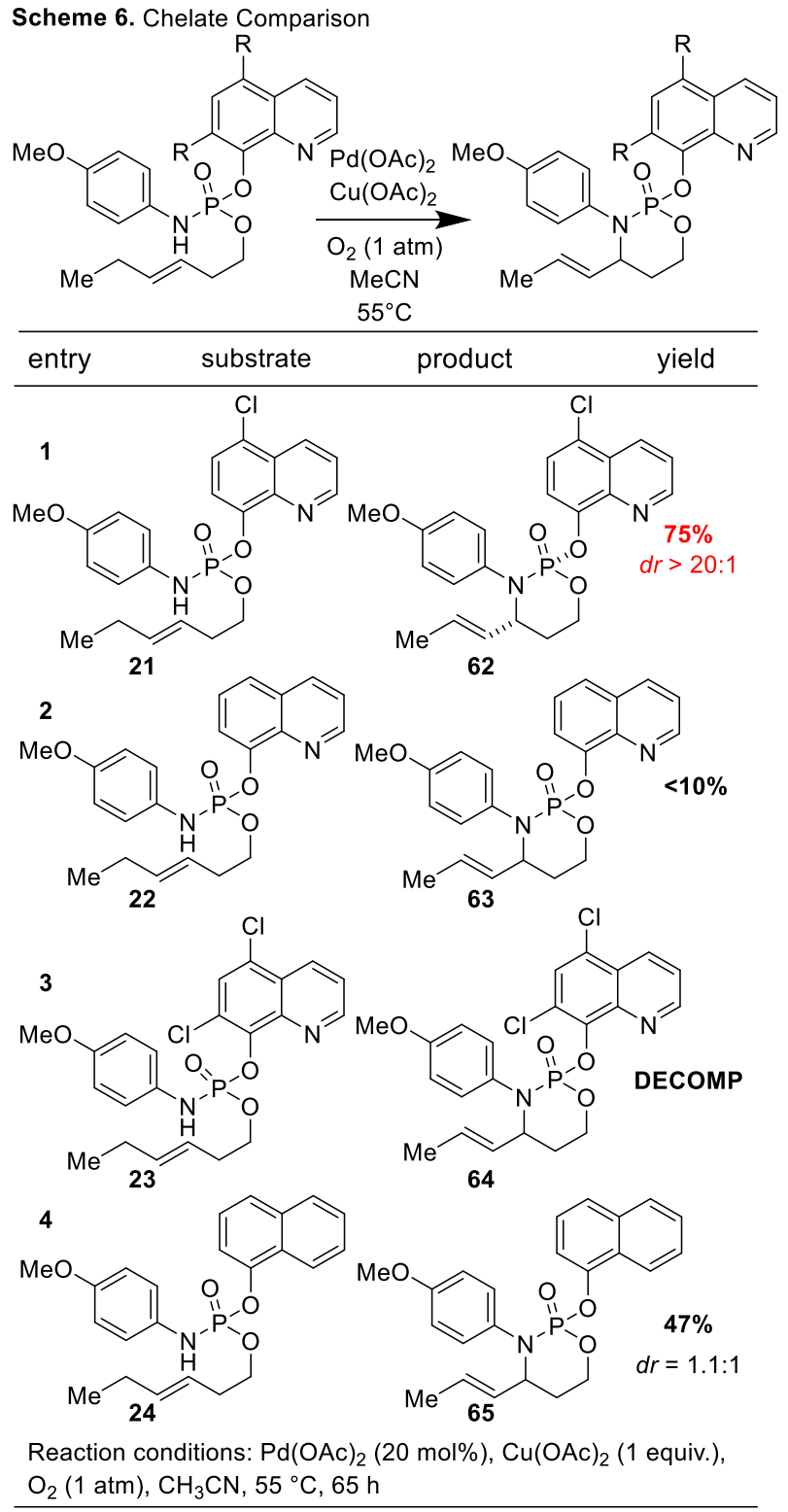

(Scheme 7, Entry 1) were also well-tolerated. Cis-olefins were compatible (Scheme 7, Entry 2) but yielded product in slightly lower yields relative to the equivalent trans-olefins. Trans-olefins containing cyclohexyl, cyclopentyl, and Boc-protected alcohols (Scheme 7, Entry 4) furnished cyclized products in good yields. The phosphoramidate tether could be appended to phenols (Scheme 7, Entry 5) as well as to secondary alcohols (Scheme 7, Entry 6). In all cases, the reactions proceeded with perfect diastereocontrol with respect to the newly formed nitrogen containing stereocenter and the phosphorous stereocenter of the phosphoramidate tether.

Furthermore, the reaction could be scaled greater than ten-fold without much diminishment of product yields; in this larger-scale reaction, product was again furnished as a single diastereomer (Scheme 8). With the 5-chloro-8-quinolinoxide auxiliary, we were no longer constrained to just using $p$-anisidine; a 
variety of anilines engaged in good yield and with greater than 20:1 diastereoselectivity (Scheme 9).

Scheme 7. Substrate Scope with Auxiliary-Induced Diastereocontrol
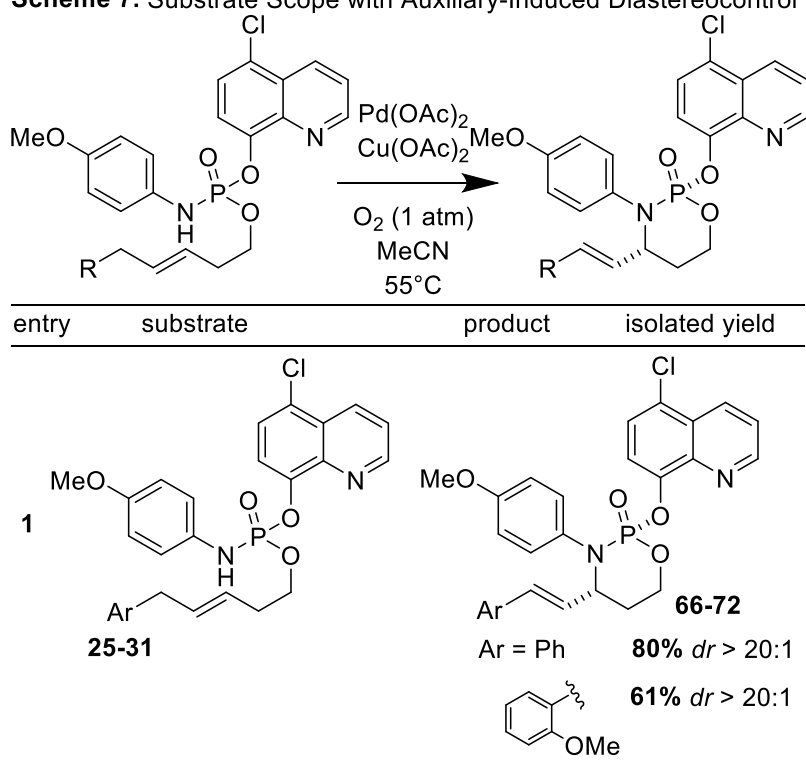

OMe

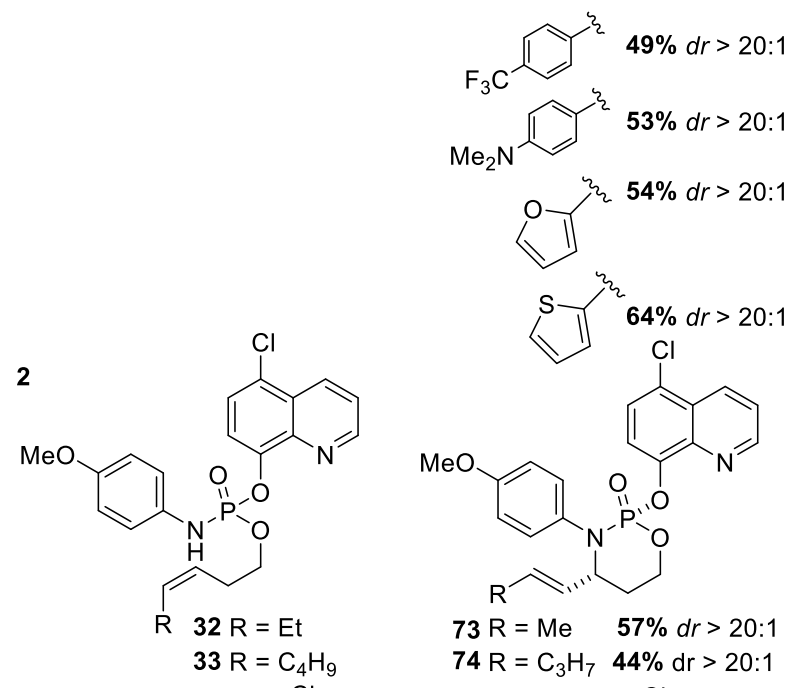

(1)

Reaction conditions: $\mathrm{Pd}(\mathrm{OAc})_{2}(20 \mathrm{~mol} \%), \mathrm{Cu}(\mathrm{OAc})_{2}$ (1 equiv.),

$\mathrm{O}_{2}(1 \mathrm{~atm}), \mathrm{CH}_{3} \mathrm{CN}, 55^{\circ} \mathrm{C}, 65 \mathrm{~h}$
Scheme 7. Continued
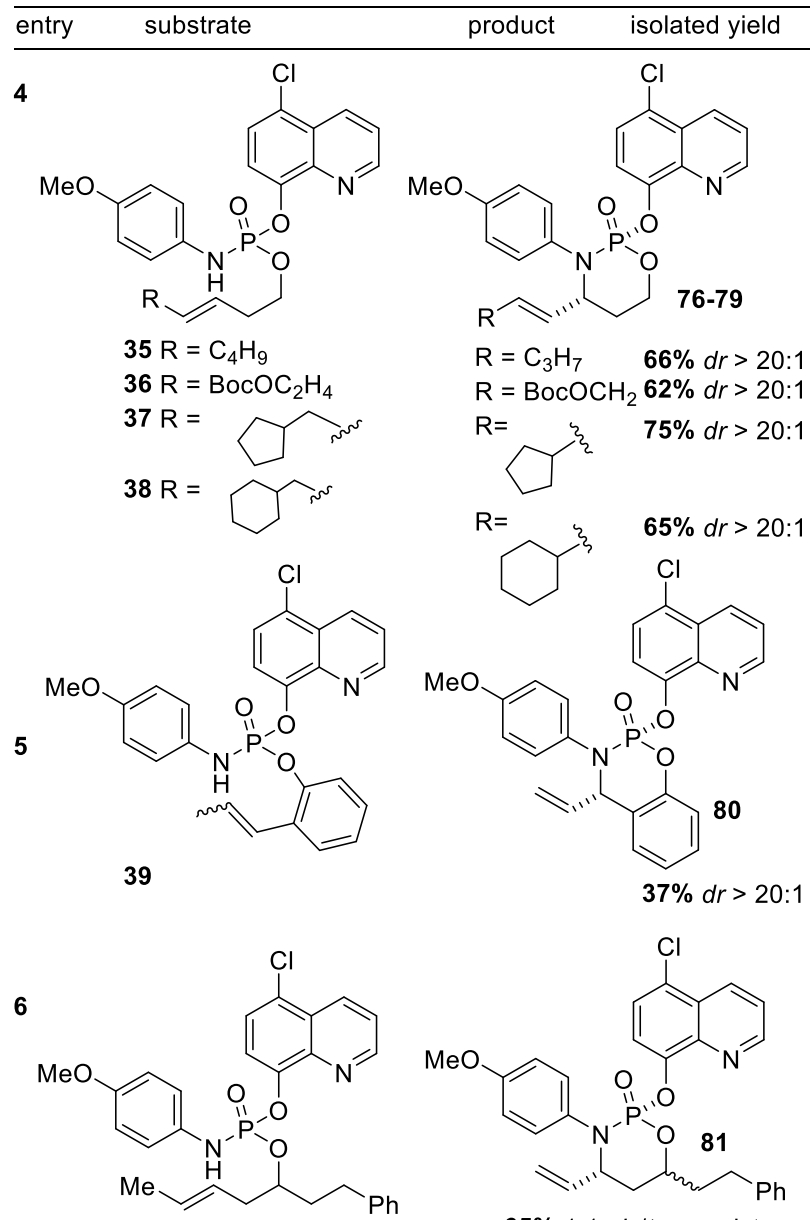

$37 \% d r>20: 1$

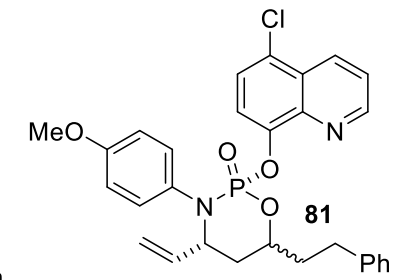

40

65\% 1:1 cis/trans mixture
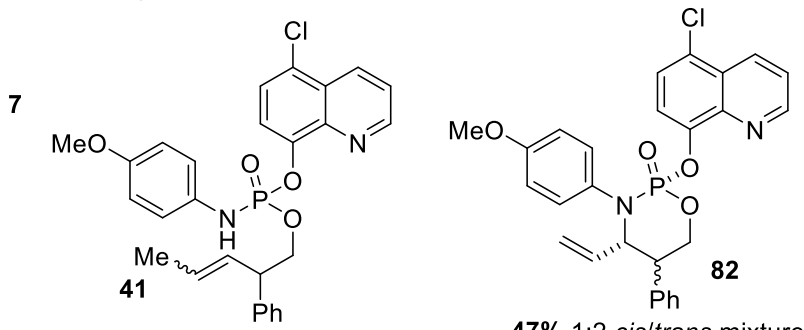

47\% $1: 2$ cis/trans mixture Reaction conditions: $\mathrm{Pd}(\mathrm{OAc})_{2}(20 \mathrm{~mol} \%), \mathrm{Cu}(\mathrm{OAc})_{2}$ (1 equiv.), $\mathrm{O}_{2}(1 \mathrm{~atm}), \mathrm{CH}_{3} \mathrm{CN}, 55^{\circ} \mathrm{C}, 65 \mathrm{~h}$

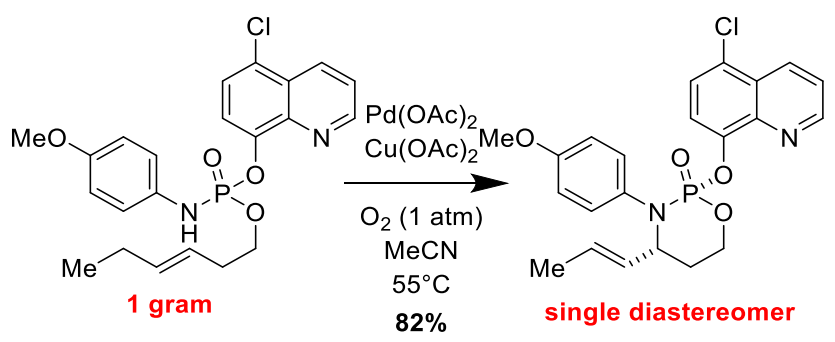

Scheme 8. Oxidative cyclization scales successfully. 
Scheme 9. Aniline Scope with Auxiliary-Induced Diastereocontrol.
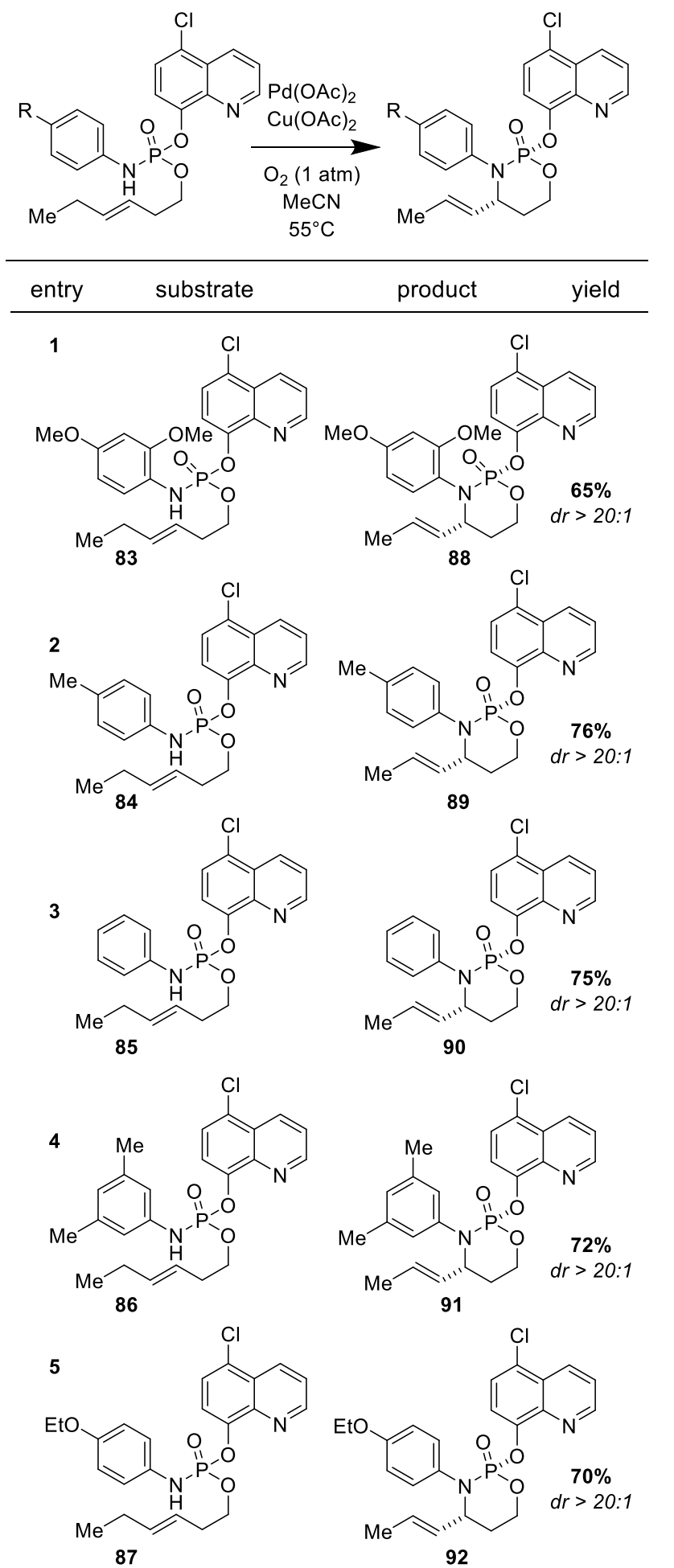

Reaction conditions: $\mathrm{Pd}(\mathrm{OAc})_{2}(20 \mathrm{~mol} \%), \mathrm{Cu}(\mathrm{OAc})_{2}$ (1 equiv.), $\mathrm{O}_{2}$ (1 atm), $\mathrm{CH}_{3} \mathrm{CN}, 55^{\circ} \mathrm{C}, 65 \mathrm{~h}$

The product cyclophosphoramidates were quite versatile. The phosphorous auxiliary could be removed by reduction with lithium aluminum hydride (Scheme 10A). Upon heating with $\mathrm{HCl}$ in dioxane, alkenyl azetidine product formed in reasonable yield (Scheme 10B). Finally, epoxidation of the pendant alkene proceeded smoothly with $m \mathrm{CPBA}$ (Scheme 10C).
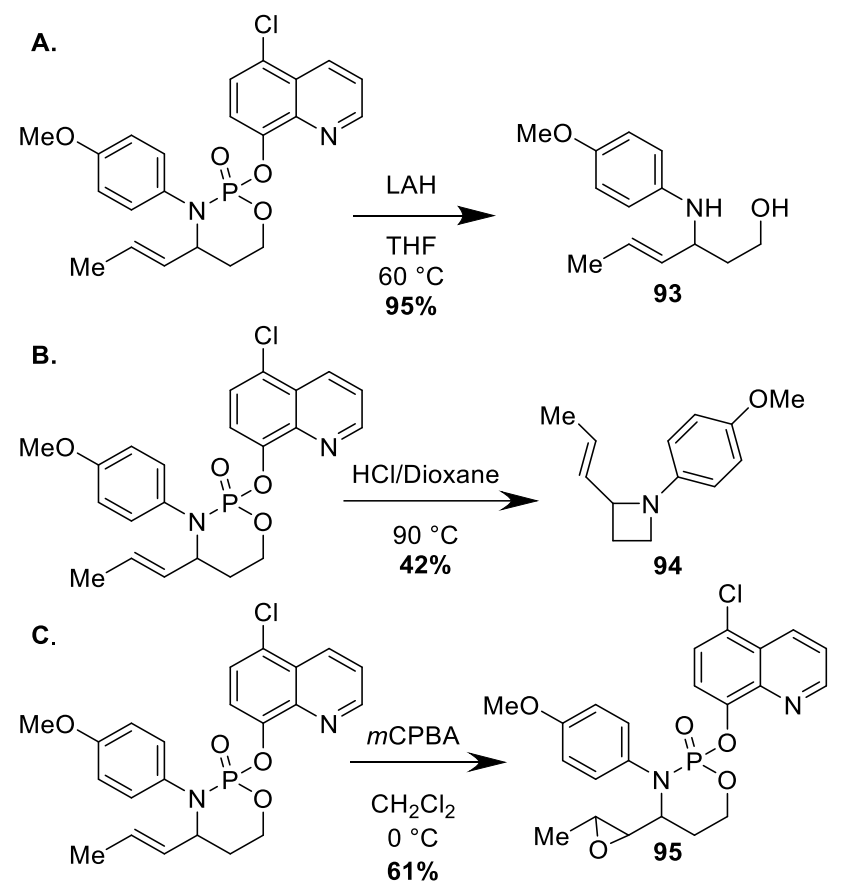

Scheme 10. A. Removal of the phosphorous tether using $\mathrm{LAH}$ reduction. B. Treatment with $\mathrm{HCl} /$ Dioxane led to azetidine formation C. Epoxidation proceeded smoothly with $m$ CPBA.

The power of a highly diastereoselective oxidative cyclization reaction is further illustrated in Scheme 11. Phosphoramidate 21 was separated into enantiomers using chiral reversed-phase HPLC. Subjecting each to our optimized $\mathrm{Pd}(\mathrm{OAc})_{2} / \mathrm{Cu}(\mathrm{OAc})_{2}$ protocol afforded enantiopure cyclic phosphoramidate products. The absolute structure and conformation of (+)-62 were determined by x-ray crystallography (CCDC: 2061647). As tether removal is possible with LAH (Scheme 10A), this allows for the synthesis of chiral amino alcohols from readily available acyclic precursors.

\section{Conclusion}

In summary, we present a protocol for highly diastereoselective tethered $a z a$-Wacker cyclization reactions of alkenyl phosphoramidates. We found that phosphoramidate tethers containing a 5-chloro-8-quinolinoxide "arm" were essential for diastereoselective cyclizations. We hypothesize that such diastereoselectivity arises from a palladium chelation, and we have identified the molecular ion of a putative chelate using high resolution electrospray ionization mass spectrometry. The substrate scope with respect to the alkenyl alcohol and the phosphoramidate tether was extensively explored. In addition, the scalablility of the cyclization reaction was demonstrated, and the product cyclophosphoramidates were shown to be valuable synthons for 
a variety of further transformations, including tether removal. With chiral alkenyl precursors, enantiopure cyclic phosphoramidates were formed.

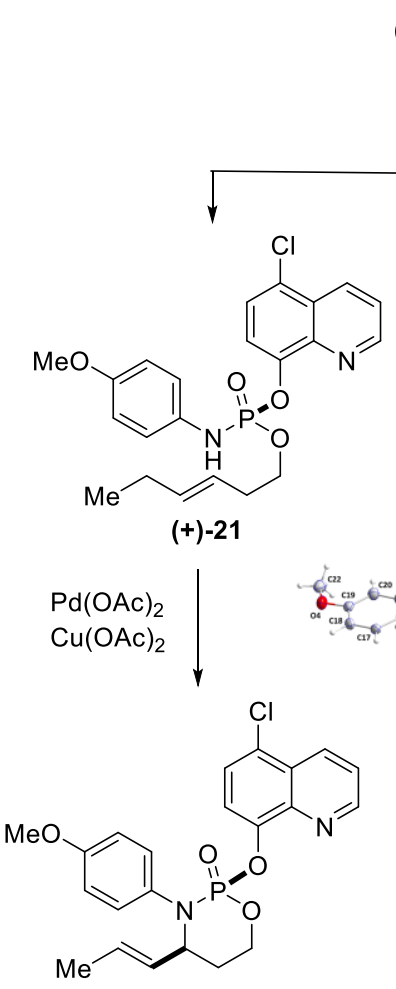

$(-)-62,74 \%$
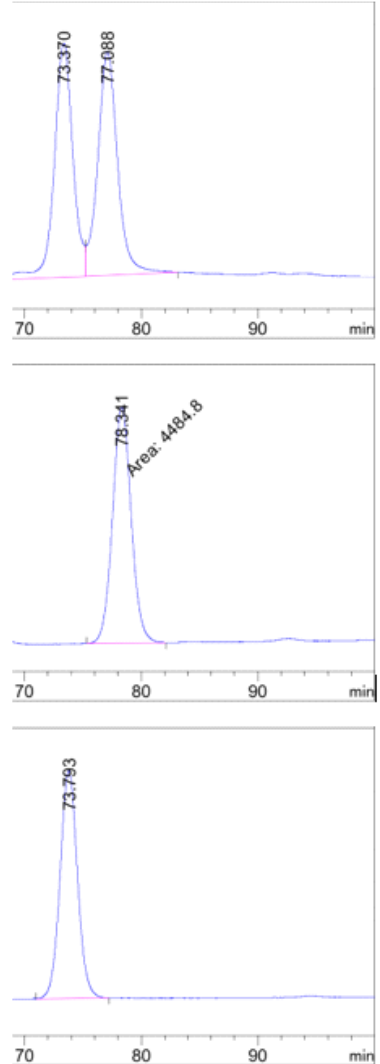

Scheme 11. Chiral resolution and highly diastereoselective oxidative cyclization reactions afford enantiopure cyclic phosphoramidates. Note: CCDC 2061647

\section{ASSOCIATED CONTENT}

Supporting Information. Experimental procedures, characterization of substrates and products, and spectra. "This material is available free of charge via the Internet at http://pubs.acs.org."

\section{AUTHOR INFORMATION}

\section{Corresponding Author}

*ssathyam@ku.edu

\section{Author Contributions}

†Anand H. Shinde and Annu Anna Thomas contributed equally.

\section{ACKNOWLEDGMENT}

This work was supported by start-up funding provided jointly by the University of Kansas Office of the Provost and the Department of Medicinal Chemistry, an NIH COBRE Chemical Biology of Infectious Diseases Research Project Grant (P20GM113117), and a New Faculty General Research Fund Grant. We gratefully acknowledge Tracy Hartlage and Dr. Weston Umstead of Chiral Technologies, Inc. for timely donation of a CHIRALPAK-IJ column for separation of phosphoramidate enantiomers.

\section{REFERENCES}

1. Cristina Silva Costa, D., Additions to nonactivated alkenes: Recent advances. Arabian Journal of Chemistry 2020, 13, 799-834.

2. Beller, M.; Seayad, J.; Tillack, A.; Jiao, H., Catalytic Markovnikov and anti-Markovnikov Functionalization of Alkenes and Alkynes: Recent Developments and Trends. Angewandte Chemie International Edition 2004, 43, 3368-3398.

3. Choi, G. J.; Knowles, R. R., Catalytic Alkene Carboaminations Enabled by Oxidative ProtonCoupled Electron Transfer. Journal of the American Chemical Society 2015, 137, 9226-9229.

4. Quinn, R. K.; Schmidt, V. A.; Alexanian, E. J., Radical carbooxygenations of alkenes using hydroxamic acids. Chemical Science 2013, 4, 40304034.

5. Trend, R. M.; Ramtohul, Y. K.; Ferreira, E. M.; Stoltz, B. M., Palladium-Catalyzed Oxidative Wacker Cyclizations in Nonpolar Organic Solvents with Molecular Oxygen: A Stepping Stone to Asymmetric Aerobic Cyclizations. Angewandte Chemie International Edition 2003, 42, 2892-2895.

6. Ma, K.; Martin, B. S.; Yin, X.; Dai, M., Natural product syntheses via carbonylative cyclizations. Natural Product Reports 2019, 36, 174219. 
7. O’Duill, M. L.; Engle, K. M., Protodepalladation as a Strategic Elementary Step in Catalysis. Synthesis 2018, 50, 4699-4714.

8. White, D. R.; Bornowski, E. C.; Wolfe, J. P., Pd-Catalyzed $\mathrm{C}-\mathrm{C}, \mathrm{C}-\mathrm{N}$, and $\mathrm{C}-\mathrm{O}$ Bond-Forming Difunctionalization Reactions of Alkenes Bearing Tethered Aryl/Alkenyl Triflates. Israel Journal of Chemistry 2020, 60, 259-267.

9. Kotov, V.; Scarborough, C. C.; Stahl, S. S., Palladium-Catalyzed Aerobic Oxidative Amination of Alkenes: Development of Intra- and Intermolecular Aza-Wacker Reactions. Inorganic Chemistry 2007, 46, 1910-1923.

10. Shinde, A. H.; Sathyamoorthi, S., Tethered Silanoxymercuration of Allylic Alcohols. Organic Letters 2020, 22, 8665-8669.

11. Kou, X.; Shao, Q.; Ye, C.; Yang, G.; Zhang, W., Asymmetric Aza-Wacker-Type Cyclization of NTs Hydrazine-Tethered Tetrasubstituted Olefins: Synthesis of Pyrazolines Bearing One Quaternary or Two Vicinal Stereocenters. Journal of the American Chemical Society 2018, 140, 7587-7597.

12. Borelli, T.; Brenna, S.; Broggini, G.; Oble, J.; Poli, G., (Diacyloxyiodo)benzenes-Driven PalladiumCatalyzed Cyclizations of Unsaturated NSulfonylamides: Opportunities of Path Selection. Advanced Synthesis \& Catalysis 2017, 359, 623-628.

13. van Benthem, R. A. T. M.; Hiemstra, H.; Longarela, G. R.; Speckamp, W. N., Formamide as a superior nitrogen nucleophile in palladium(II) mediated synthesis of imidazolidines. Tetrahedron Letters 1994, 35, 9281-9284.

14. Beccalli, E. M.; Broggini, G.; Paladino, G.; Penoni, A.; Zoni, C., Regioselective Formation of Sixand Seven-Membered Ring by Intramolecular PdCatalyzed Amination of N-Allyl-anthranilamides. The Journal of Organic Chemistry 2004, 69, 5627-5630.

15. McDonald, R. I.; Stahl, S. S., Modular Synthesis of 1,2-Diamine Derivatives by PalladiumCatalyzed Aerobic Oxidative Cyclization of Allylic Sulfamides. Angewandte Chemie International Edition 2010, 49, 5529-5532.

16. Joosten, A.; Persson, A. K. Å.; Millet, R.; Johnson, M. T.; Bäckvall, J.-E., Palladium(II)Catalyzed Oxidative Cyclization of Allylic Tosylcarbamates: Scope, Derivatization, and Mechanistic Aspects. Chemistry - A European Journal 2012, 18, 15151-15157.

17. Weinstein, A. B.; Schuman, D. P.; Tan, Z. X.; Stahl, S. S., Synthesis of Vicinal Aminoalcohols by Stereoselective Aza-Wacker Cyclizations: Access to (-)-Acosamine by Redox Relay. Angewandte Chemie International Edition 2013, 52, 11867-11870.
18. Shinde, A. H.; Sathyamoorthi, S., Oxidative Cyclization of Sulfamates onto Pendant Alkenes. Organic Letters 2020, 22, 896-901.

19. Shinde, A. H.; Nagamalla, S.; Sathyamoorthi, S., N-arylated oxathiazinane heterocycles are convenient synthons for 1,3-amino ethers and 1,3amino thioethers. Medicinal Chemistry Research 2020, 29, 1223-1229.

20. Cheon, C. H.; Yamamoto, H., Super Brønsted acid catalysis. Chemical Communications 2011, 47, 3043-3056.

21. Oliveira, F. M.; Barbosa, L. C. A.; Ismail, F. M. D., The diverse pharmacology and medicinal chemistry of phosphoramidates - a review. RSC Advances 2014, 4, 18998-19012.

22. Lu, H.; Tao, J.; Jones, J. E.; Wojtas, L.; Zhang, X. P., Cobalt(II)-Catalyzed Intramolecular $\mathrm{C}-\mathrm{H}$ Amination with Phosphoryl Azides: Formation of 6and 7-Membered Cyclophosphoramidates. Organic Letters 2010, 12, 1248-1251.

23. Xiao, W.; Wei, J.; Zhou, C.-Y.; Che, C.-M., [RuIV(F20-TPP)Cl2] efficiently catalysed inter- and intra-molecular nitrene insertion into $\mathrm{sp} 3 \mathrm{C}-\mathrm{H}$ bonds of hydrocarbons using phosphoryl azides as nitrene sources. Chemical Communications 2013, 49, 46194621.

24. Betancor, C.; Concepcion, J. I.; Hernandez, R.; Salazar, J. A.; Suarez, E., Intramolecular functionalization of nonactivated carbons by amidylphosphate radicals. Synthesis of 1,4-epimine compounds. The Journal of Organic Chemistry 1983, 48, 4430-4432.

25. Francisco, C. G.; Herrera, A. J.; Martín, Á.; Pérez-Martín, I.; Suárez, E., Intramolecular 1,5hydrogen atom transfer reaction promoted by phosphoramidyl and carbamoyl radicals: synthesis of 2-amino-C-glycosides. Tetrahedron Letters 2007, 48, 6384-6388.

26. Francisco, C. G.; Herrera, A. J.; Suárez, E., Intramolecular Hydrogen Abstraction Reaction Promoted by N-Radicals in Carbohydrates. Synthesis of Chiral 7-Oxa-2-azabicyclo[2.2.1]heptane and 8Oxa-6-azabicyclo[3.2.1]octane Ring Systems. The Journal of Organic Chemistry 2003, 68, 1012-1017.

27. Martín, A.; Pérez-Martín, I.; Suárez, E., Synthesis of oxa-aza spirobicycles by intramolecular hydrogen atom transfer promoted by $\mathrm{N}$-radicals in carbohydrate systems. Tetrahedron 2009, 65, 61476155 .

28. He, J.; Wasa, M.; Chan, K. S. L.; Shao, Q.; Yu, J.-Q., Palladium-Catalyzed Transformations of Alkyl C-H Bonds. Chemical Reviews 2017, 117, 8754-8786. 29. Lyons, T. W.; Sanford, M. S., PalladiumCatalyzed Ligand-Directed $\mathrm{C}-\mathrm{H}$ Functionalization Reactions. Chemical Reviews 2010, 110, 1147-1169. 
30. Dey, A.; Agasti, S.; Maiti, D., Palladium catalysed meta-C-H functionalization reactions. Organic \& Biomolecular Chemistry 2016, 14, 54405453.

31. Chen, X.; Engle, K. M.; Wang, D.-H.; Yu, J.Q., Palladium(II)-Catalyzed C-H Activation/C-C Cross-Coupling Reactions: Versatility and Practicality. Angewandte Chemie International Edition 2009, 48, 5094-5115.

32. Giri, R.; Shi, B.-F.; Engle, K. M.; Maugel, N.; Yu, J.-Q., Transition metal-catalyzed $\mathrm{C}-\mathrm{H}$ activation reactions: diastereoselectivity and enantioselectivity. Chemical Society Reviews 2009, 38, 3242-3272.

33. Derosa, J.; Tran, V. T.; Boulous, M. N.; Chen, J. S.; Engle, K. M., Nickel-Catalyzed $\beta, \gamma-$ Dicarbofunctionalization of Alkenyl Carbonyl Compounds via Conjunctive Cross-Coupling. Journal of the American Chemical Society 2017, 139, 10657 10660.
34. Gurak, J. A.; Yang, K. S.; Liu, Z.; Engle, K. M., Directed, Regiocontrolled Hydroamination of Unactivated Alkenes via Protodepalladation. Journal of the American Chemical Society 2016, 138, 58055808 .

35. Liu, Z.; Zeng, T.; Yang, K. S.; Engle, K. M., $\beta, \gamma$-Vicinal Dicarbofunctionalization of Alkenyl Carbonyl Compounds via Directed Nucleopalladation. Journal of the American Chemical Society 2016, 138, 15122-15125.

36. Yang, K. S.; Gurak, J. A.; Liu, Z.; Engle, K. M., Catalytic, Regioselective Hydrocarbofunctionalization of Unactivated Alkenes with Diverse $\mathrm{C}-\mathrm{H}$ Nucleophiles. Journal of the American Chemical Society 2016, 138, 14705-14712. 
Insert Table of Contents artwork here

Phosphoramidate Tethered Aza-Wacker Cyclization

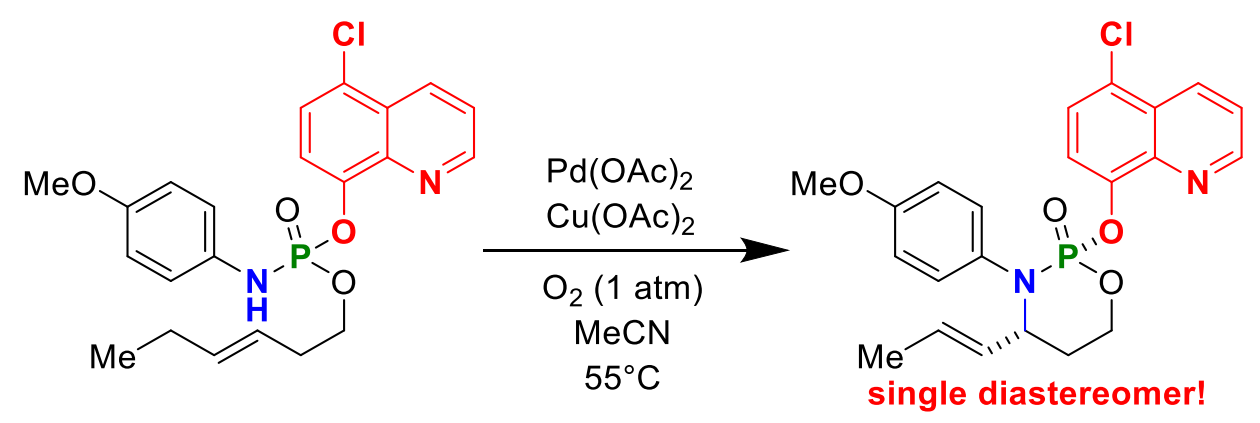

